\title{
Development of the Hebrew-Multidimensional Inventory of Dissociation (H-MID): A Valid and Reliable Measure of Pathological Dissociation
}

\author{
Eli Somer, $\mathrm{PhD}$ \\ Paul F. Dell, PhD
}

\begin{abstract}
The Multidimensional Inventory of Dissociation (MID; Dell, 2004b) has 168 dissociation items and 50 validity items. The MID assesses 14 major facets of dissociation, 23 symptoms of dissociation, and has 5 validity scales. The MID operationalizes (a) the subjective/ phenomenological domain of dissociation, and (b) 23 hypothesized symptoms of dissociative identity disorder (DID). This article describes the development of a Hebrew version of the MID (H-MID). In a sample of clinical and nonclinical research participants, the H-MID had strong internal consistency, temporal stability, and strong structural, convergent, discriminant, and construct validity. In addition, mean H-MID scores demonstrated incremental validity over the Hebrew Dissociative Experiences Scale (H-DES) by predicting an additional $17 \%$ of the variance in weighted trauma scores on the Traumatic Experiences Questionnaire (TEQ). Factor analysis of the H-MID extracted a single factor: dissociation. Both the MID and the subjective/phenomenological con-
\end{abstract}

Eli Somer is affiliated with the School of Social Work, University of Haifa, Israel, and is Senior Clinical Psychologist and Director of Training at Maytal-Israel Institute for Treatment and Study of Stress, Haifa, Israel.

Paul F. Dell is affiliated with the Trauma Recovery Center, Psychotherapy Resources of Norfolk, Norfolk, VA.

Address corresponding to: Eli Somer, PhD, School of Social Work, University of Haifa, Mt. Carmel, Haifa 31905, Israel (E-mail: somer@ research.haifa.ac.il).

The authors acknowledge the helpful assistance of Shai Levinger, MA, with the translation and adaptation of the MID into the Hebrew language.

Journal of Trauma \& Dissociation, Vol. 6(1) 2005

http://www.haworthpress.com/web/JTD

(C) 2005 by The Haworth Press, Inc. All rights reserved.

Digital Object Identifier: 10.1300/J229v06n01_03 
cept of pathological dissociation appear to have applicability not only in North America, but also in a heterogeneous Middle Eastern culture. [Article copies available for a fee from The Haworth Document Delivery Service: 1-800-HAWORTH. E-mail address: <docdelivery@haworthpress.com> Website: <http://www.HaworthPress.com> (C) 2005 by The Haworth Press, Inc. All rights reserved.]

KEYWORDS. Multidimensional Inventory of Dissociation, MID, assessment, dissociation, Hebrew

Dissociation has been called an "unfortunately vague term" (Marshall, Spitzer, \& Liebowitz, 1999, p. 1681). Historically, this has been all too true; there have been many different understandings of "dissociation" (Van der Hart \& Dorahy, in press). In fact, there continues to be debate about (1) the definition of dissociation, (2) its neuroanatomical and neurophysiological mechanisms or explanations, (3) its psychological mechanisms or explanations, and (4) its domain of phenomena (Braude, 1995; Cardeña, 1994; Dell, 2004a).

The most heated area of debate has focused on the psychological explanation of dissociation. For example, many clinicians who treat dissociative patients consider dissociative symptoms to be caused by split-off parts of the mind or personality. On the other hand, sociocognitive theorists have argued that dissociative "symptoms" are behavioral enactments that have been shaped by therapists and the media (e.g., Lilienfeld, Kirsch, Sarbin, Lynn, Chaves, Ganaway, \& Powell, 1999). Although the authors' conceptual allegiances clearly lie with the former rather than the latter, the Multidimensional Inventory of Dissociation (MID) does not address itself to the mechanisms of dissociation, psychological or otherwise. Instead, like all other measures of dissociation, the MID addresses only the "phenomena" of dissociation.

Admittedly, any measure of dissociation must have some conceptual, empirical, or theoretical underpinnings. For example, the underpinning of the Structured Clinical Interview of DSM-IV Dissociative Disorders-Revised (SCID-D-R; Steinberg, Rounsaville, \& Cicchetti, 1990) is DSM-IV (American Psychiatric Association, 2000). Because the SCID$\mathrm{D}-\mathrm{R}$ is a diagnostic instrument for the DSM-IV dissociative disorders, the DSM-IV diagnostic criteria directly specified which dissociative symptoms must be assessed by the SCID-D-R.

Similarly, the Dissociative Experiences Scale (DES; Bernstein \& Putnam, 1986) has its own underpinning. The DES was based upon two major theses: (1) that the domain of dissociative phenomena could be 
represented by a continuum that stretches from normal phenomena (such as daydreaming or absorption) to major clinical pathology (such as amnesia or dissociative identity disorder; DID); and (2) that the phenomenal domain of dissociation is characterized by at least three significant clusters of dissociative phenomena: Amnesia, depersonalization/derealization, and absorption (Bernstein \& Putnam, 1986; Waller, Putnam, \& Carlson, 1996).

So what are the underpinnings of the MID? The MID was founded upon three underlying "girders": (1) the subjective/phenomenological concept of dissociation (Dell, in press), (2) the subjective/phenomenological domain of dissociation (Dell, in press), and (3) the taxon model of pathological dissociation (Waller et al., 1996).

The taxon model of pathological dissociation explicitly rejects both premises upon which the DES was founded (i.e., the continuum model of dissociation and the three-cluster portrayal of dissociation: absorption, depersonalization/derealization, and amnesia). In a nutshell, the taxon model holds that all manifestations of dissociation are pathological, and that normal forms of dissociation do not exist. Absorption, for example, which many clinicians consider to be a normal form of dissociation, is specifically excluded from the concept of pathological dissociation.

The taxon model does two important things. First, it adheres to Janet's $(1889,1907)$ view of dissociation (i.e., that dissociative symptoms are inherently pathological). Second, it explicitly rejects the model of dissociation that has dominated the dissociative disorders field for the past several decades-the continuum model. The taxon model holds that the phenomena on the normal end of the continuum are not manifestations of dissociation.

The subjective/phenomenological concept of dissociation (Dell, in press) is loosely rooted in Karl Jasper's phenomenological approach to psychopathology (Jaspers, 1963/1997). This model of dissociation is also indebted to the work of another German phenomenological psychiatrist, Kurt Schneider. Schneider (1959) enumerated 11 first-rank symptoms of schizophrenia which he claimed were pathognomonic of schizophrenia: (1) voices arguing, (2) voices commenting, (3) "made" feelings, (4) "made" impulses, (5) "made" actions, (6) influences playing on the body, (7) thought insertion, (8) thought withdrawal, (9) thought broadcasting, (10) audible thoughts, and (11) delusional perception.

Kluft (1987) reported that the first eight of Schneider's first-rank symptoms were common in patients with DID, but that the last three 
were not. Dell noted that these eight first-rank symptoms had something in common: Each is a peculiar intrusion into the person's executive functioning and/or sense of self. Reflecting on his proposed diagnostic criteria for DID (Dell, 2001a), Dell conjectured that all dissociative symptoms could be described as being intrusions into executive functioning and/or the person's sense of self (Dell, in press). Thus, schizophrenics experience psychotic forms of intrusion (e.g., "John Ashcroft is implanting his thoughts in my head."), whereas dissociative patients experience nonpsychotic intrusions (e.g., "Sometimes I have thoughts that do not feel like they are mine.").

The subjective/phenomenological concept of dissociation (Dell, in press) provides a phenomenological definition of pathological dissociation: Recurrent intrusions into executive functioning and the person's sense of self. This concept of dissociation also specifies the domain of dissociative phenomena: The entirety of human experience (Dell, in press). This latter point is essential. Intrusions into executive functioning and sense of self can (and do) occur in every aspect of human experience: Thinking, believing, knowing, recognizing, remembering, feeling, wanting, speaking, acting, seeing, hearing, smelling, tasting, touching (i.e., body sensations), and so on.

The subjective/phenomenological model of dissociation does not specify the cause of these dissociative intrusions. This, in fact, is necessarily the case because it is not an explanatory model; it is a phenomenological model. This means that the subjective/phenomenological model of dissociation is neutral with regard to the cause of dissociation. Consequently, the model is congruent with a variety of competing explanations of dissociative phenomena.

The MID operationalizes the domain of dissociative phenomena (i.e., the entirety of human experience) via 23 dissociative symptoms. These 23 dissociative symptoms also constitute the dissociative symptom-domain of DID. They might be called the " 23 first-rank symptoms of DID." 1

\section{THE MULTIDIMENSIONAL INVENTORY OF DISSOCIATION (MID)}

The MID is a self-report, multiscale measure of pathological dissociation that was developed to (a) embody the subjective/phenomenological concept of dissociation (Dell, in press), (b) operationalize the 
subjective/phenomenological domain of dissociation, and (c) test the subjective/phenomenological concept of dissociative identity disorder (DID; Dell, 2001a, 2001b, 2004c). To date, MID research in five languages has strongly supported (1) the subjective/phenomenological concept of dissociation (Dell, 2004a, 2004c), (2) the subjective/phenomenological domain of dissociation (Dell, 2004a, 2004c), (3) the subjective/phenomenological concept of DID (Dell, 2001b, 2004c; Gast et al., 2003), and (4) the validity and reliability of the MID (Dell, 2001b, 2002, 2004b).

Factor analytic studies of the MID have supported its structural validity. A large-sample $(N=1,359)$ factor analysis of the MID's 168 dissociation items produced a 12-factor solution that closely corresponded to both the 14 facet scales and the 23 dissociation diagnostic scales (Dell, 2004a). That is, each of the 14 facets and 23 dissociative symptoms correlated most highly with a conceptually similar factor. When the factor scores of the 12 factors were subjected to hierarchical factor analysis, a single factor was extracted: Dissociation (Dell, 2004a).

The format of the MID is very similar to that of the DES. The MID has an 11-point Likert scale (0-10) that is anchored by the words "Never" and "Always." The instructions are as follows: "How often do you have the following experiences when you are not under the influence of alcohol or drugs? Please circle the number that best describes you. Circle a " 0 " if the experience never happens to you; circle a " 10 " if it is always happening to you. If it happens sometimes, but not all the time, circle a number between " 1 " and " 9 " that best describes how often it happens to you."

Because mean MID scores are multiplied by 10, they lie on the same 0-100 metric as the DES. This allows easy comparison between MID scores and findings in the DES literature. Unlike previous measures of dissociation, the MID contains validity scales. The MID assesses five response sets that often occur in patients who have a mixture of dissociative, posttraumatic, and borderline symptoms: Defensive minimization, strong negative reactions to daily stressors (i.e., negative affectivity), indiscriminate reporting of bizarre and improbable symptoms, attention-seeking behavior, and deliberate exaggeration and falsification of symptoms and trauma history.

The MID was developed in the United States. The purpose of the current study was to examine the MID's applicability to a different culture. In Israel, papers on dissociation have been presented at conferences and published in journals (e.g., Margalit \& Wiztum, 1997a, 1997b; Somer, 1987, 1989, 1993, 1994, 1995; Somer \& Somer, 1997). Dissociation re- 
search in Israel has also contributed to the development and validation of the first dissociation assessment tool in Israel-the Hebrew DES (H-DES). The H-DES has demonstrated excellent reliability and validity (Somer, Dolgin, \& Saadon, 2001).

We developed a Hebrew version of the MID and evaluated its reliability and validity when administered to Israeli clinical and nonclinical samples.

\section{STUDY 1}

\section{Method}

\section{Participants}

The first study used a nonclinical snowball sample. A snowball sample relies on the researcher's ability to locate an initial set of respondents with desired characteristics. In this case, the desired characteristic was the willingness to spend 90-120 minutes completing research questionnaires; these individuals were used as informants to identify still others who were similarly motivated to participate in this research. Eighty-five undergraduate students attending a course titled, "Introduction to Psychology," were invited to anonymously participate in the study. They were also asked to invite a friend or family member to complete a second set of research questionnaires. Students who returned two completed research packets received an academic bonus credit.

One hundred and fifty-one research packets were returned. Four were identical and were suspected to be copies. Four were incomplete, and two were blatantly over-endorsed and were suspected to be invalid "all-yes" response sets. Thus the study was based upon 141 participants (an $83 \%$ return rate). Participants were 38 men and 103 women (mean age $=28.4$ years; $S D=7.8$ ).

\section{Materials}

Multidimensional Inventory of Dissociation (MID). A 218-item, selfreport, multiscale measure of pathological dissociation, the MID has 14 non-overlapping 12-item primary facet scales and 23 scales that measure the hypothesized symptoms of DID (Dell, 2001a) (see Table 1). It is important to note that the 14 facet scales and the 23 dissociation diagnostic scales are alternate apportionments of the MID's 168 dissocia- 
TABLE 1. Internal consistency (Cronbach alpha values) and temporal stability coefficients of the Hebrew Multidimensional Inventory of Dissociation (H-MID)

\begin{tabular}{|c|c|c|c|c|}
\hline & & Study 1 & Study 2 & \\
\hline Scale & No. of Items & Alpha & Alpha & Test-Retest \\
\hline H-MID & 168 & .99 & .99 & .98 \\
\hline H-MID Facet Scales & 14 & .95 & .98 & $\mathrm{n} / \mathrm{a}$ \\
\hline H-MID Diagnostic Scales & 23 & .96 & .98 & $\mathrm{n} / \mathrm{a}$ \\
\hline Memory problemsa, b & 12 & .88 & .94 & .90 \\
\hline Depersonalizationa, b & 12 & .88 & .94 & .97 \\
\hline Derealizationa, b & 12 & .87 & .95 & .93 \\
\hline Flashbacksa, b & 12 & .92 & .96 & .89 \\
\hline Somatoform symptomsa, b & 12 & .71 & .88 & .85 \\
\hline Trance $a, b$ & 12 & .78 & .94 & .95 \\
\hline Identity confusiona & 12 & .93 & .96 & .91 \\
\hline Voicesa & 12 & .87 & .96 & .91 \\
\hline Ego-alien experiences ${ }^{a}$ & 12 & .89 & .95 & .90 \\
\hline Self-alteration $\mathrm{a}, \mathrm{b}$ & 12 & .82 & .92 & .91 \\
\hline Self-states/altersa & 12 & .82 & .96 & .98 \\
\hline Discontinuities of timea & 12 & .78 & .92 & .88 \\
\hline Disremembered behaviora & 12 & .69 & .89 & .89 \\
\hline Ancillarya & 12 & .82 & .91 & .93 \\
\hline Child voicesb & 3 & .56 & .82 & .97 \\
\hline Internal struggleb & 9 & .86 & .94 & .89 \\
\hline Persecutory voicesb & 5 & .62 & .93 & .88 \\
\hline Speech insertionb & 3 & .71 & .86 & .95 \\
\hline Thought insertion ${ }^{b}$ & 5 & .84 & .91 & .93 \\
\hline 'Made'/intrusive emotions' & 7 & .94 & .95 & .93 \\
\hline 'Made'/intrusive impulses'b & 3 & .78 & .85 & .89 \\
\hline 'Made'/intrusive actions' ${ }^{b}$ & 9 & .90 & .94 & .90 \\
\hline Loss of knowledgeb & 5 & .66 & .84 & .88 \\
\hline Self-puzzlementb & 8 & .90 & .95 & .98 \\
\hline Time loss $b$ & 4 & .63 & .87 & .95 \\
\hline Coming to ${ }^{b}$ & 4 & .57 & .79 & .89 \\
\hline Fugues $^{b}$ & 5 & .24 & .80 & .96 \\
\hline Being told of actions ${ }^{b}$ & 4 & .57 & .76 & .85 \\
\hline Finding objects & 4 & .51 & .65 & .81 \\
\hline Finding evidence of actions ${ }^{b}$ & 5 & .10 & .70 & .82 \\
\hline
\end{tabular}

$\mathrm{a}_{\text {The }} 14$ dissociation facet scales

$\mathrm{b}_{\text {The }} 23$ dissociation diagnostic scales 
tion items. Seven of the 23 dissociation diagnostic scales are the same as identically-named facet scales. There is a small degree of item overlap across the remaining 16 dissociation diagnostic scales.

The MID has five validity scales that were designed to facilitate accurate diagnoses in patients who present with an admixture of dissociative, posttraumatic, and borderline symptoms: Defensiveness, Rare Symptoms, Emotional Suffering, Attention-Seeking Behavior, and Factitious Behavior.

MID research (Dell, 2004b) has reported excellent internal consistency (i.e., Cronbach alpha coefficient $=.99$ ) and excellent temporal stability (i.e., four- to eight-week test-retest reliability $=.97$ ). The MID's convergent validity was demonstrated by its correlations with five other measures of dissociation: (1) Questionnaire of Experiences of Dissociation (QED; $r=.75$; Riley, 1988), (2) Somatoform Dissociation Questionnaire (SDQ-20; $r=.75$; Nijenhuis, Spinhoven, Van Dyck, Van der Hart, \& Vanderlinden, 1996), (3) SCID-D-R ( $r=.78)$, (4) Dissociation Questionnaire (DIS-Q; $r=.83$; Vanderlinden, Van Dyck, Vandereycken, Vertommen, \& Verkes, 1993), and (5) DES ( $r=.90)$.

Four studies have supported the MID's discriminant validity (Dell, 2000, 2004a, 2004b; Gast et al., 2003). The MID has repeatedly demonstrated its ability to successfully discriminate among normal adults, mixed psychiatric patients, patients with depersonalization disorder, patients with dissociative disorder not otherwise specified (DDNOS), and patients with DID.

The MID's construct validity has been supported by its relationship with history of trauma $(r=.63)$, symptoms of PTSD $(r s=.55$ to .72$)$, identity impairment $(r=.63)$, and personality styles that are known to be typical of persons with DID (Dell, 2004b): Being socially inhibited, nonassertive, overly accommodating, and self-sacrificing (Bjornson, Reagor, \& Kasten, 1988; Dell, 1998, 2002c; Ellason, Ross, \& Fuchs, 1995, 1996; Fink \& Golinkoff, 1990). Finally, the MID has demonstrated incremental validity over the DES in predicting history of trauma (Dell, 2004b).

Dissociative Experiences Scale-Hebrew Version (H-DES). The DES (Bernstein \& Putnam, 1986; Carlson \& Putnam, 1993) measures the frequency of 28 dissociative experiences. The DES has been shown to be a valid and reliable screening instrument (Frischholtz et al., 1990; Waller, 1996); it is the most used measure of dissociation in the published literature. The Hebrew translation of the DES (H-DES) has high reliability and validity (Somer et al., 2001). The test-retest reliability coefficient was .87. The split-half reliability coefficient (Spearman-Brown) was 
.86. Internal consistency (Cronbach alpha coefficient) was .91. Convergent validity was estimated by comparing scores of the H-DES with scores of the Phillips Dissociation Scale (PDS), a 20-item instrument derived from the MMPI-2 (Phillips, 1994). The Spearman correlation between the H-DES and the PDS scores for 284 patients was .59. Divergent validity was estimated by comparing the scores of the H-DES and the Masculinity-Femininity (Mf) scale of the MMPI-2. There was no significant correlation between these two scales $(r=-.03)$ (Somer et al., 2001).

Traumatic Experiences Questionnaire-Hebrew Version (H-TEQ). The TEQ (Nijenhuis et al., 1998) is a self-report questionnaire that assesses 25 potentially traumatizing life events. When participants endorse items that pertain to interpersonal violence, the TEQ 'asks' the subjects to indicate (a) whether they were hurt by immediate family members, relatives, or others, (b) the duration and frequency of the abuse, and (c) the developmental era (i.e., ages 0-6, 7-12, 13-18) during which the abuse occurred. Subjects also rate the impact of each endorsed stressor. The original version of the TEQ (Nijenhuis et al., 1998) has subsequently been modified and relabeled as the Traumatic Experiences Checklist (Nijenhuis, Van der Hart, \& Kruger, 2002). The present study used the original version of the TEQ. The TEQ/TEC has very good internal consistency (Cronbach alpha coefficients that range from .86 to .90). Test-retest reliability is .91 (Nijenhuis, 1999). Construct validity of both the TEQ and the construct of dissociation have been supported by moderate correlations between TEQ scores and several other variables: Physical abuse, sexual abuse, psychological dissociation, and somatoform dissociation (Nijenhuis et al., 1998).

The TEQ was translated into Hebrew by the first author (a native Hebrew speaker) and was then blindly back-translated into English by a Hebrew-speaking, native English speaker. The back-translation was compared to the original version and differences were reconciled. The final Hebrew version of the TEQ (H-TEQ) was used in this study. The H-TEQ assesses the number of traumatic experiences (0-25) that a person has experienced. Weighted trauma scores are assigned on the basis of four factors: (1) the presence or absence of the trauma, (2) the duration of the trauma (i.e., less than a year vs. more than a year), (3) whether the trauma was due to perpetrators from the person's nuclear family, and (4) the rated subjective impact of the trauma. Weighted scores (0-12) were given for three developmental periods of life (ages 0-6, ages 7-12, and ages 13-18) for five kinds of abuse (i.e., emotional neglect, emotional abuse, physical abuse, sexual harassment, 
and sexual abuse). A total weighted trauma score was obtained by summing the above. Total weighted trauma scores can range from 0 to 60 .

Translation of the MID into Hebrew. An earlier 259-item version of the MID was translated into Hebrew by two bilingual, native Hebrew-speaking individuals (i.e., the first author and a research assistant). A professional English-Hebrew translator, who was blind to the English language MID, back-translated the items into English. The first author then compared the original and back-translated English versions. Twenty-two of the 259 items were discrepant and required retranslation. The resulting Hebrew translation was used.

\section{Results}

Data were collected with the 259-item MID 4.0, but all data analyses reported below are based on the revised MID (6.0) (i.e., a 218-item scoring of the MID 4.0's 259 items). The MID 6.0 was developed by deleting 41 items from the MID 4.0. Development of the MID 6.0 was based solely on North American MID data (Dell, 2004b). The 218-item MID 6.0 contains 168 dissociation items and 50 validity items.

\section{Internal Consistency of the H-MID}

When treated as a 168 -item test (i.e., the 168 dissociation items), the H-MID had a Cronbach alpha coefficient of .99. When treated as a 14-item test (i.e., the 14 facet scales), the H-MID had a Cronbach alpha coefficient of .95 . When treated as a 23 -item test (i.e., the 23 dissociation diagnostic scales), the H-MID had a Cronbach alpha coefficient of .96.

The internal consistencies of the 14 facet scales (Table 1) ranged from poor (i.e., less than .70); to excellent (i.e., .90 or greater); the internal consistency of nine of the 23 diagnostic scales was poor (i.e., less than .70).

Factor Structure of the H-MID's 14 Facet Scales and 23 Diagnostic Scales

When scores on the 14 facet scales were subjected to principal axis factor analysis, only one factor could be extracted: Dissociation. This factor had an eigenvalue of 9.2 and accounted for $68.2 \%$ of the variance in the 14 scales. When scores on the 23 dissociation diagnostic scales were subjected to principal axis factor analysis, two factors were extracted: (1) Partially-Dissociated Intrusions (eigenvalue $=13.2$ ) and (2) Fully-Dissociated Intrusions (eigenvalue $=1.6$ ). These factors explained $57.4 \%$ and $7.0 \%$ of the variance, respectively. Hierarchical fac- 
tor analysis of the factor scores extracted one factor: Dissociation. Limitations of sample size $(N=142)$ precluded conducting a factor analysis of the H-MID's 168 dissociation items.

\section{Convergent Validity}

Mean H-MID scores correlated .70 with mean H-DES scores (Table 2). Correlations between the H-DES and the H-MID's 14 facet scales ranged from .52 to .69 . Correlations between the H-DES and the H-MID's 23 dissociation diagnostic scales ranged from .28 to .69.

\section{Construct Validity of the H-MID}

Construct validity of the H-MID was assessed by examining the correlations between dissociation and reported trauma (i.e., between H-MID scores and H-TEQ scores; Table 3). Only the H-MID's correlation with number of traumas was significant $(p<.01)$. No other correlations between the H-MID and the H-TEQ were significant.

\section{Discussion}

The psychometrics of the H-MID were often poor. First, the H-MID correlated only .70 with the H-DES. Second, the internal consistency of many H-MID scales was poor. Third, the H-MID's correlations with the H-TEQ were abysmally low. North American research, using these same instruments, had produced much stronger results.

The authors concluded that there were two likely sources of the poor performance of the H-MID: (1) an unknown number of inadequately translated items, and (2) questionable motivation in the student research participants. In a later debriefing, several students admitted that they were only marginally motivated to participate in this study. Others reported that they had been uncertain about the meaning of some H-MID items. Study 2 was designed to remedy both of these issues.

\section{STUDY 2}

\section{Revision of the Hebrew Translation of the MID}

Step 1

Eighteen students who participated in Study 1 underwent an exit interview during which their responses to the H-MID were reviewed. 
TABLE 2. H-MID correlations with other measures of dissociation

\begin{tabular}{|c|c|c|c|}
\hline & \multirow{2}{*}{$\frac{\text { Study } 1}{\text { H-DES }}$} & \multicolumn{2}{|c|}{ Study 2} \\
\hline & & H-DES & SCID-D-R \\
\hline H-MID Scale & $N=141$ & $N=130$ & $N=34$ \\
\hline Mean H-DES & 1.00 & 1.00 & .82 \\
\hline Mean H-MID & .70 & .91 & .89 \\
\hline Memory problems & .57 & .70 & .72 \\
\hline Depersonalization & .56 & .87 & .88 \\
\hline Derealization & .69 & .82 & .82 \\
\hline Flashbacks & .54 & .77 & .67 \\
\hline Somatoform symptoms & .58 & .77 & .73 \\
\hline Trance & .58 & .83 & .85 \\
\hline Identity confusion & .62 & .82 & .83 \\
\hline Voices & .58 & .83 & .73 \\
\hline Ego-alien experiences & .63 & .89 & .81 \\
\hline Self-alteration & .57 & .89 & .85 \\
\hline Self-states/alters & .52 & .83 & .78 \\
\hline Discontinuity of time & .58 & .87 & .74 \\
\hline Disremembered behavior & .53 & .88 & .72 \\
\hline Ancillary & .68 & .89 & .79 \\
\hline Child voices & .56 & .78 & .72 \\
\hline Internal struggle & .54 & .86 & .78 \\
\hline Persecutory voices & .53 & .79 & .70 \\
\hline Speech insertion & .56 & .85 & .80 \\
\hline Thought insertion & .57 & .80 & .73 \\
\hline 'Made'/intrusive emotions & .62 & .83 & .75 \\
\hline 'Made'/intrusive impulses & .45 & .82 & .77 \\
\hline 'Made'/intrusive actions & .64 & .86 & .82 \\
\hline Loss of knowledge & .62 & .87 & .72 \\
\hline Self-puzzlement & .63 & .80 & .80 \\
\hline Time loss & .59 & .81 & .71 \\
\hline Coming to & .45 & .83 & .74 \\
\hline Fugues & .44 & .74 & .54 \\
\hline Told of actions & .47 & .82 & .73 \\
\hline Finding objects & .28 & .68 & .47 \\
\hline Evidence of actions & .53 & .82 & .68 \\
\hline
\end{tabular}

Note. H-MID = Herbrew Multidimensional Inventory of Dissociation; H-DES = Hebrew Dissociative Experiences Scale; SCID-D-R = Structured clinical interview for DSM-IV Dissociative Disorders-Revised. 
TABLE 3. Correlations between dissociation and reported trauma

\begin{tabular}{lccccc}
\hline & \multicolumn{2}{c}{ Study 1 } & \multicolumn{2}{c}{ Study 2} \\
\hline H-TEQ scale & H-MID & H-DES & H-MID & H-DES & SCID-D-R \\
& $N=140$ & $N=140$ & $N=125$ & $N=125$ & $N=32$ \\
\hline Number of traumas & $.36^{\mathrm{b}}$ & $.28^{\mathrm{b}}$ & $.70^{\mathrm{c}}$ & $.61^{\mathrm{c}}$ & $.54^{\mathrm{c}}$ \\
Weighted trauma score & .14 & .11 & $.70^{\mathrm{c}}$ & $.58^{\mathrm{c}}$ & $.54^{\mathrm{c}}$ \\
Emotional neglect & .07 & .08 & $.61^{\mathrm{c}}$ & $.47^{\mathrm{C}}$ & $.42^{\mathrm{a}}$ \\
Emotional abuse & .19 & .12 & $.61^{\mathrm{c}}$ & $.53^{\mathrm{c}}$ & $.50^{\mathrm{c}}$ \\
Physical abuse & .01 & .02 & $.53^{\mathrm{c}}$ & $.45^{\mathrm{c}}$ & $.30^{2}$ \\
Sexual harassment & .00 & .02 & $.57^{\mathrm{c}}$ & $.47^{\mathrm{c}}$ & $.41^{\mathrm{a}}$ \\
Sexual abuse & .11 & .10 & $.64^{\mathrm{c}}$ & $.53^{\mathrm{c}}$ & $.44^{\mathrm{a}}$ \\
Age 0-6 & .07 & .09 & $.71^{\mathrm{c}}$ & $.57^{\mathrm{c}}$ & $.51^{\mathrm{c}}$ \\
Age 7-12 & .11 & .05 & $.66^{\mathrm{c}}$ & $.64^{\mathrm{c}}$ & $.51^{\mathrm{c}}$ \\
Age 13-18 & .16 & .14 & $.69^{\mathrm{c}}$ & $.60^{\mathrm{c}}$ & $.49^{\mathrm{c}}$ \\
\hline
\end{tabular}

Note: $\mathrm{H}-\mathrm{TEQ}=$ Hebrew Traumatic Experiences Scale; H-MID = Hebrew Multidimensional Inventory of Dissociation; H-DES = Hebrew Dissociative Experiences Scale; SCID-D-R = Hebrew Structured Clinical Interview for DSM-IV Dissociative Disorders-Revised.

$\mathrm{a}_{(p<.05)} \mathrm{b}_{(p<.01)}{ }^{\mathrm{C}}(p<.001)$

Based on these interviews and item-total correlations, 48 H-MID items were determined to be weak, problematic, or frequently misunderstood.

Examples of Misunderstood Items. Several examples of misunderstood items are listed as follows: (1) "Having trance-like episodes where you stare off into space and lose awareness of what is going on around you." This item and similar items were misunderstood because the Hebrew language does not have a word for "trance." To ensure proper understanding of "trance," we added the descriptor "hypnotic" to clarify what was meant; (2) "Strong thoughts in your head that "come from out of nowhere." In order to reduce awkwardness in Hebrew, we found a substitute for the word "strong"; (3) "Having blank spells or blackouts in your memory." In Hebrew, there are no equivalent words for blank spells or blackouts. We reworded our translation to better describe the experiences; (4) " Coming to" in the middle of a conversation with someone and having no idea what you and that person have been talking about-you didn't even know that you were having a conversation." Our original translation of "coming to" was misunderstood. We provided several related synonyms to clarify the meaning of the experience. 
The first author and a bi-lingual research assistant refined the translation of the suspect items. To ensure the equivalency of the Hebrew and English versions of these items, the dissociative experiences described by these 48 discrepant items were carefully reviewed with the second author. Items that could not be properly translated, due to the lack of linguistically equivalent words in Hebrew, were not translated literally. Instead, they were either rewritten as a somewhat different description of the dissociative experiences in question or they were rewritten according to their meaning in Hebrew. The discrepant items were then subjected to blind back-translation by a professional Hebrew-English translator and further review by the first author.

\section{Step 2}

To ensure stylistic and grammatical acceptability of the revised H-MID, the new items were given to a professional Hebrew-English editor for review. The editor made slight editorial alterations in item phrasing.

\section{Step 3}

The 48 items were again compared with the Hebrew translation and the original English version to determine if meanings had been changed. A bilingual psychologist who was blind to the previous phases of the translation participated in this step. No items required retranslation. This final version of the H-MID was employed in Study 2.

\section{METHOD}

\section{Participants}

Because we questioned the motivation of the subjects in Study 1, we made an effort to recruit a judgment sample that would be comprised of highly motivated respondents. A judgment sample is a nonprobability sample (often called a purposive sample); the sample elements are handpicked in order to serve the research purpose. Graduate students, academics, mental health professionals, and patients who agreed to anonymously reply to the research questionnaires were the subjects for Study 2. One hundred and thirty people participated (a 96\% response rate). Ninety-six (74\%) were nonclinical (65 women and 31 men; mean 
age $=33.3$ years, sampled from the School of Social Work graduate classes and University of Haifa administrative and academic staff) and $34(26 \%)$ were patients or consultees of the first author (27 women and 7 men; mean age $=34.2$ years; $S D=5.3$ ).

\section{Materials}

Participants completed the same three questionnaires that were used in Study 1: H-MID (now revised), H-DES, and H-TEQ. In addition, clinical participants were administered the SCID-D-R in Hebrew.

Structured Clinical Interview for DSM-IV Dissociative DisordersRevised (SCID-D-R; Steinberg, Cicchetti, Buchanan, Hall, \& Rounsaville, 1993). The SCID-D-R is a clinician-administered interview that yields a four-point rating (1-4) for each of five symptoms of dissociation: Amnesia, depersonalization, derealization, identity confusion, and identity alteration. The SCID-D-R has been shown to have excellent reliability and discriminant validity (Steinberg et al., 1990, 1993). The instrument had been previously translated by the first author and his colleagues (Somer et al., 2001). In the present study the Hebrew version of the SCID-D-R was administered by the first author to 34 consenting patients or consultees referred to him for assessment or treatment.

\section{RESULTS}

\section{Internal Consistency of the Revised H-MID}

When treated as a 168 -item test (i.e., the 168 dissociation items), the H-MID had a Cronbach alpha coefficient of .99. When treated as a 14-item test (i.e., the 14 facet scales), the H-MID had a Cronbach alpha coefficient of .98. When treated as a 23 -item test (i.e., the 23 dissociation diagnostic scales), the H-MID had a Cronbach alpha coefficient of .98 .

Table 1 shows that the alpha values of the H-MID's scales were considerably higher in Study 2 than in Study 1. The alpha coefficients for the 14 facet scales were .88 or higher. The alpha coefficients for the 23 dissociation diagnostic scales were much higher than those from Study 1: 11 were excellent (i.e., alpha values of .90 or higher), 7 were good (i.e., alpha values of .80 or higher), 3 were fair (i.e., alpha values of .70 or higher), and 1 was poor (i.e., alpha value less than .70). 
Temporal Stability of the Revised H-MID

H-MID scores were remarkably stable over a 3- to 4-week interval (Table 1). Test-retest reliability coefficients ranged from a low of .80 for the 4-item Finding Objects Scale to .98 for the mean MID score.

Factor Structure of the Revised H-MID's 14 Facet Scales and 23 Diagnostic Scales

When scores on the 14 facet scales were subjected to principal axis factor analysis, only one factor could be extracted: Dissociation. This factor had an eigenvalue of 11.3 and accounted for $80.6 \%$ of the variance in the 14 facet scales. When scores on the 23 dissociation diagnostic scales were subjected to principal axis factor analysis, only one factor could be extracted: Dissociation. This factor had an eigenvalue of 17.4 and accounted for $75.6 \%$ of the variance in the 23 diagnostic scales. Limitations of sample size $(N=131)$ precluded conducting a factor analysis of the H-MID's 168 dissociation items.

Convergent Validity of the Revised H-MID

$H$-DES. H-MID scores correlated .91 with H-DES scores. Correlations between the H-DES and the H-MID's 14 facet scales ranged from .70 to .89 (median $r=.85$ ). Correlations between the H-DES and the H-MID's 23 dissociation diagnostic scales ranged from .68 to .87 (median $r=.82$ ) (see Table 2).

$S C I D-D-R$. H-MID scores correlated .89 with SCID-D-R total scores. Correlations between the SCID-D-R and the H-MID's 14 facet scales ranged from .67 to .88 (median $r=.79$ ). Correlations between the SCID-D-R and the H-MID's 23 dissociation diagnostic scales ranged from .47 to .88 (median $r=.72$ ).

\section{Discriminant Validity of the Revised H-MID}

Three one-way ANOVAs (i.e., SCID-D-R total score: $F(4,29)=$ $79.75, p<.001$; H-MID mean score: $F(4,30)=24.78, p<.001$; and H-DES mean score: $F(4,30)=13.51, p<.001)$ each significantly discriminated among five SCID-D-R-diagnosed groups: DID, DDNOS, depersonalization disorder, dissociative amnesia, and patients without a dissociative diagnosis (Table 4). Post hoc Scheffé comparisons showed that H-MID mean scores had greater discriminant capacity than H-DES 
TABLE 4. Comparison of dissociation scores for five SCID-D-R-diagnosed groups

\begin{tabular}{|l|c|c|c|c|c|c|r|}
\hline & \multicolumn{3}{|c|}{ SCID-D-R } & \multicolumn{2}{c|}{ H-MID } & \multicolumn{2}{c|}{ H-DES } \\
\hline Diagnostic group & $\boldsymbol{N}$ & $\boldsymbol{M}$ & $\boldsymbol{S} \boldsymbol{D}$ & $\boldsymbol{M}$ & $\boldsymbol{S} \boldsymbol{D}$ & $\boldsymbol{M}$ & $\boldsymbol{S} \boldsymbol{D}$ \\
\hline & & & & & & & \\
\hline DID & 4 & $18.75_{\mathrm{b}}$ & 1.26 & $54.75_{\mathrm{b}}$ & 16.88 & $51.93_{\mathrm{b}}$ & 25.46 \\
\hline DDNOS & 6 & $15.00_{\mathrm{b}}$ & 1.58 & $29.20_{\mathrm{ab}}$ & 14.07 & $22.02_{\mathrm{a}}$ & 4.68 \\
\hline Depersonalization & 4 & $11.75_{\mathrm{a}}$ & 2.50 & $22.20_{\mathrm{a}}$ & 11.44 & 20.98 & 18.36 \\
\hline Amnesia & 2 & $10.00_{\mathrm{a}}$ & 1.60 & $9.29_{\mathrm{a}}$ & 1.60 & 14.47 & 5.81 \\
\hline No dissociative diagnosis & 19 & $5.74_{\mathrm{a}}$ & 1.28 & $5.48_{\mathrm{a}}$ & 5.70 & 6.89 & 6.72 \\
\hline
\end{tabular}

Note. Means in the same column that do not share subscripts differ at $p<.01$ in the Scheffé comparison. SCID-D-R = Structured Clinical Interview for DSM-IV Dissociative Disorders; H-MID = Hebrew Multidimensional Inventory of Dissociation; H-DES = Hebrew Dissociative Experiences Scale; DID = dissociative identity disorder; DDNOS = dissociative disorder not otherwise specified; Depersonalization $=$ depersonalization disorder; Amnesia = dissociative amnesia; No dissociative diagnosis = patients who do not have a dissociative diagnosis.

Significantly lower than DID $(p<.01)$

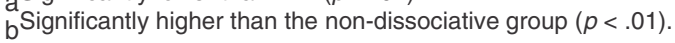

mean scores and comparable discriminant capacity to SCID-D-R total scores.

\section{Construct Validity of the Revised H-MID}

Construct validity of the H-MID was assessed by examining the correlations between dissociation and reported trauma (i.e., between H-MID scores and H-TEQ scores). In sharp contrast to the results of Study 1, mean H-MID scores correlated significantly with all scales of the H-TEQ (Table 3). Similarly, the H-DES correlated significantly with all H-TEQ scales and the SCID-D-R correlated significantly with all but one H-TEQ scale.

\section{Incremental Validity of the $H-M I D$}

H-MID scores consistently correlated more highly with H-TEQ scores than did H-DES scores or SCID-D-R scores. Hierarchical regression analysis demonstrated that the H-MID demonstrated incremental validity over the DES in predicting weighted trauma scores on the H-TEQ (Table 5). When H-DES mean scores were controlled for, H-MID mean scores predicted an additional $17 \%$ of the variance of H-TEQ weighted trauma scores. 
TABLE 5. Hierarchical regression analysis for measures of dissociation predicting weighted trauma scores on the Traumatic Experiences Questionnaire $(N=125)$

\begin{tabular}{|l|c|c|c|c|c|}
\hline Measure of dissociation & $\boldsymbol{B}$ & $\boldsymbol{S E}$ & $\beta$ & $\boldsymbol{R}^{2}$ & $\Delta \boldsymbol{R}^{\mathbf{2}}$ \\
\hline & & & & & \\
\hline Step 1 & & & & & \\
\hline DES & .87 & .11 & $.58^{\star *}$ & & \\
\hline & & & & $.34^{\star *}$ & $.34^{\star *}$ \\
\hline Step 2 & & & & & \\
\hline DES & -.45 & .22 & $-.30^{*}$ & & \\
\hline H-MID mean score & 1.25 & .19 & $.98^{\star *}$ & & \\
\hline & & & & $.51^{* *}$ & $.17^{* *}$ \\
\hline Step 3 & & & & & \\
\hline DES & -.44 & .22 & $-.29^{*}$ & & \\
\hline H-MID mean score & .23 & .37 & .18 & & \\
\hline H-MID severe dissociation & .39 & .12 & $.82^{* *}$ & & \\
\hline & & & & $.55^{\star *}$ & $.04^{*}$ \\
\hline
\end{tabular}

Note DES = Dissociative Experiences Scale; MID = Multidimensional Inventory of Dissociation; H-MID severe dissociation $=\mathrm{H}-\mathrm{MID}$ severe dissociation score. ${ }^{*} \mathrm{p}<.05 ;{ }^{* *} p<.01$

\section{GENERAL DISCUSSION}

The H-MID is a valid and psychometrically robust, multiscale measure of pathological dissociation. The H-MID had strong internal consistency temporal stability, and structural, convergent, and discriminant validity. It also showed incremental validity over the H-DES in predicting history of trauma. In short, the H-MID seems to share the same psychometric strengths and construct validity that are possessed by the original MID (Dell, 2004a, 2004b) and the German MID (G-MID; Gast, et al., 2003).

The internal consistency and the temporal stability of the H-MID's scales are similar to those of the MID and the G-MID. The nearly unitary alpha values of the H-MID as a 14-item scale (.98) and as a 23-item scale (.98) have been found in four other countries: United States (Dell, 2004b), Germany (Gast et al., 2003), Italy (Montesanto, 2004), and The Philippines (Gingrich, 2004). 
When treated as a 14-item scale, the H-MID had a one-factor structure. Similarly, when treated as a 23-item scale, the H-MID had a one-factor structure. These findings are in keeping with several other factor analytic studies of the MID. To date, all factor analyses of the MID have yielded either a first-order unifactorial solution or a second-order unifactorial solution (Dell, 2004a). This robust finding confers substantial validity upon (1) the MID, (2) the subjective/phenomenological concept of dissociation that informed its development, and (3) the subjective/phenomenological domain of dissociation that it operationally defined.

The H-MID correlated .91 with the H-DES and .89 with SCID-D-R total scores. These findings are almost identical to findings in the United States (Dell, 2004b) and Germany (Gast et al., 2003). Like other versions of the MID, the H-MID has excellent convergent validity.

Despite the very small group sizes, the H-MID demonstrated impressive discriminant validity. These data are congruent with three other studies that have validated the MID's ability to discriminate among different diagnostic groups (Dell, 2004a, 2004b; Gast et al., 2003).

The ability of the H-MID to predict a person's reported history of trauma was especially impressive. In doing so, the H-MID replicated earlier North American data that showed the MID's ability to predict TEQ scores. Moreover, the H-MID data replicated previous research that demonstrated the MID's incremental validity over the DES in predicting the impact of trauma (Dell, 2004a).

Four limitations to this study should be noted. First, the clinician who collected the SCID-D-R data (first author) was not blind to the validating agenda of the study. On the other hand, the likelihood that this circumstance skewed the data is mitigated by the similarity of our findings to those of three previous studies of the MID's discriminant validity. Second, the sample size of the different SCID-D-R-diagnosed groups was very small. Still, given the very small size of the diagnostic groups, the H-MID's ability to discriminate among those groups is impressive. Nevertheless, the study should be repeated with larger groups. Future H-MID research should investigate the instrument's ability to discriminate among large samples of independently assessed diagnostic groups, including borderline personality disorder, PTSD, dissociative disorders of movement and sensation (i.e., conversion disorder), and schizophrenia. Third, although the problems and the resultant substandard findings in Study 1 were addressed and successfully corrected in Study 2, the discrepancy in the results of Study 1 and Study 2 warrants caution in the interpretation of our findings. Additional replication studies are needed. 
Fourth, this study was largely based on nonclinical subjects. Future study of the H-MID's psychometric characteristics should focus on clinical groups.

The present study lends support to (1) the validity of both the H-MID and MID, (2) the construct validity of the subjective/phenomenological concept of dissociation, and (3) the structural validity of the subjective/ phenomenological domain of dissociation. The H-MID and MID would seem to be worthy additions to the measurement armamentarium for dissociation.

\section{NOTES}

1. Schneider's first-rank symptoms were considered to be pathognomonic of schizophrenia (i.e., he believed that only schizophrenics had these symptoms). Subsequent empirical research has demonstrated that these symptoms occur in other psychotic disorders as well. Our use of the phrase first-rank symptoms of DID is not meant to suggest that these symptoms are pathognomonic of DID; they are not. We do believe, however, that when 15 or more of these symptoms occur in a single patient (in the absence of borderline exaggeration), then that person almost certainly has DID.

\section{REFERENCES}

American Psychiatric Association. (2000). Diagnostic and statistical manual of mental disorders (Fourth Edition, Text Revision). Washington, DC: American Psychiatric Association.

Bernstein, E. M., \& Putnam, F. W. (1986). Development, reliability, and validity of a dissociation scale. Journal of Nervous and Mental Disease, 174, 727-735.

Bjornson, L., Reagor, P. A., \& Kasten, J. D. (1988). Multiple personality patterns on standardized psychological tests. In B. G. Braun (Ed.), Proceedings of the Fifth International Conference on multiple personality/dissociative states (p. 101). Chicago: Rush Presbyterian-St. Luke's Medical Center.

Braude, S. E. (1995). First person plural: Multiple personality and the philosophy of mind (Rev. ed.). Lanham, MD: Rowman \& Littlefield Publishers, Inc.

Cardeña, E. (1994). The domain of dissociation. In S. J. Lynn, \& J. W. Rhue (Eds.), Dissociation: Clinical and theoretical perspectives (pp. 15-31). New York: Guilford Press.

Carlson, E. B., \& Putnam, F. W. (1993). An update on the Dissociative Experiences Scale. Dissociation, 6, 16-27.

Dell, P. F. (1998). Axis II pathology in outpatients with dissociative identity disorder. Journal of Nervous and Mental Disease, 186, 352-356.

Dell, P. F. (2001a). Should the dissociative disorders field choose its own diagnostic criteria for dissociative identity disorder? Reply to Cardeña, Coons, Putnam, Spiegel, and Steinberg. Journal of Trauma \& Dissociation, 2(1), 65-72. 
Dell, P. F. (2001b). Why the diagnostic criteria for dissociative identity disorder should be changed. Journal of Trauma \& Dissociation, 2(1), 7-37.

Dell, P. F. (2002). Dissociative phenomenology of dissociative identity disorder. Journal of Nervous and Mental Disease, 190, 10-15.

Dell, P. F. (2004a). The phenomenological domain of dissociation. Submitted for publication.

Dell, P. F. (2004b). Multidimensional Inventory of Dissociation (MID): A comprehensive measure of the subjective/phenomenological domain of dissociation. Submitted for publication.

Dell, P. F. (2004c). The subjective/phenomenological concept of dissociative identity disorder. Submitted for publication.

Dell, P. F. (in press). The subjective/phenomenological view of dissociation. In P. F. Dell, \& J. O'Neil (Eds.), Dissociation and the dissociative disorders: DSM-V and beyond. [Publisher will be provided after 9/04]

Ellason, J. W., Ross, C. A., \& Fuchs, D. L. (1995). Assessment of dissociative identity disorder with the Millon Clinical Multiaxial Inventory-II. Psychological Reports, 76, 895-905.

Ellason, J. W., Ross, C. A., \& Fuchs, D. L. (1996). Lifetime axis I and axis II comorbidity and child abuse history in dissociative identity disorder. Psychiatry, 59, 255-266.

Fink, D., \& Golinkoff, M. (1990). MPD, borderline personality disorder and schizophrenia: A comparative study of clinical features. Dissociation, 3, 127-134.

Frischholtz, E. J., Braun, B. G., Sachs, R. G., Hopkins, L., Schaeffer, D. M., Lewis, J., Leavitt, F., Pasquatto, M. A., \& Schwartz, D. R. (1990). The Dissociative Experiences Scale: Further replication and validation. Dissociation, 3, 151-153.

Gast, U., Rodewald, F., Dehner-Rau, C., Kowalewsky, E., Engl, V., Reddemann, L., \& Emrich, H. M. (2003, November). Validity and reliability of the German version of the Multidimensional Inventory of Dissociation (MID-D): Preliminary results. Paper presented at the conference of the International Society for the Study of Dissociation, Chicago, IL.

Gingrich, H. D. (2004). Dissociation in a student sample in the Philippines. Doctoral dissertation. University of the Philippines.

Janet, P. (1889). L'automatisme psychologique: Essai de psychologie expérimentale sur les formes inférieures de l'activité humaine [Psychological automatism: An experimental psychological essay on the lower forms of human activity]. Paris: Félix Alcan.

Janet, P. (1907). The major symptoms of hysteria. London/New York: Macmillan. Reprint of 1920 edition: Hafner, New York, 1965.

Jaspers, K. (1997). General psychopathology (7th ed.), Vol. I (J. Hoenig \& M.W. Hamilton, Trans.). Baltimore: Johns Hopkins University Press. (Original work published 1963)

Kluft, R. P. (1987). First-rank symptoms as a diagnostic clue to multiple personality disorder. American Journal of Psychiatry, 144, 293-298.

Lilienfeld, S. O., Kirsch, I., Sarbin, T. R., Lynn, S. J., Chaves, J. F., Ganaway, G. K., \& Powell, R. A. (1999). Dissociative identity disorder and the sociocognitive model: Recalling the lessons of the past. Psychological Bulletin, 125, 507-523. 
Marshall, R. D., Spitzer, R., \& Liebowitz, M. R. (1999). Review and critique of the new DSM-IV diagnosis of acute stress disorder. American Journal of Psychiatry, 156, 1677-1685.

Margalit, H., \& Witzum, E. (1997a). Trauma, amnesia and dissociation: Clinical and theoretical aspects. Part I: A theoretical review. Sihot-Israel Journal of Psychotherapy, 11, 214-217 (in Hebrew).

Margalit, H., \& Witzum, E. (1997b). Trauma, amnesia and dissociation: Clinical and theoretical aspects. Part II: A case report. Sihot-Israel Journal of Psychotherapy, 12, 44-50 (in Hebrew).

Montesanto, F. (2004). Dissociation in adults in Italy. Unpublished manuscript.

Nijenhuis, E. R. S. (1999). Somatoform dissociation: Phenomena, measurement, and theoretical issues. Assen, The Netherlands: Van Gorcum \& Company.

Nijenhuis, E. R. S., Spinhoven, P., Van Dyck, R., Van der Hart, O. \& Vanderlinden, J. (1996). The development and psychometric characteristics of the Somatoform Dissociation Questionnaire (SDQ-20). Journal of Nervous \& Mental Disease, 184, 688-694.

Nijenhuis, E. R. S., Spinhoven, P., Van Dyck, R., Van der Hart, O., \& Vanderlinden, J. (1998). Degree of somatoform and psychological dissociation in dissociative disorder is correlated with reported trauma. Journal of Traumatic Stress, 11, 711-730.

Nijenhuis, E. R. S., Van der Hart, O, \& Kruger, K. (2002). The psychometric characteristics of the Traumatic Experiences Checklist (TEC): First findings among psychiatric patients. Clinical Psychology and Psychotherapy, 9, 200-210.

Phillips, D. W. (1994). Initial development and validation of the Phillips Dissociation Scale (PDS) of the MMPI. Dissociation, 7, 92-100.

Riley, K. C. (1988). Measurement of dissociation. Journal of Nervous and Mental Disease, 176, 449-450.

Schneider, K. (1959). Clinical psychopathology. New York: Grune \& Stratton.

Somer, E. (1987, November). Multiple personality: Diagnosis and treatment principles. Paper presented at the Third National Conference of the Israel Hypnosis Society, Tel Aviv (in Hebrew).

Somer, E. (1989). Multiple personality disorder: Comments on diagnosis, treatment and the therapists' feelings. Sihot-Israel Journal of Psychotherapy, 3, 101-106 (in Hebrew).

Somer, E. (1993). Possession syndrome in a histrionic personality: Exorcism and psychotherapy. Sihot-Israel Journal of Psychotherapy, 8, 40-47 (in Hebrew).

Somer, E. (1994). Delayed recall of child abuse: False memories or the next challenge in psychotherapy? Sihot-Israel Journal of Psychotherapy, 9, 46-50 (in Hebrew).

Somer, E. (1995). Trauma and trance and abreaction in dissociative identity disorder. Hypnoza, 1(1), 8-15 (in Hebrew).

Somer, L., \& Somer, E. (1997). Psychodynamic perspectives on art work in dissociative identity disorder. Sihot-Israel Journal of Psychotherapy, 11, 183-194 (in Hebrew).

Somer, E., Dolgin, M., \& Saadon, M. (2001). Validation of the Hebrew version of the Dissociative Experiences Scale (H-DES) in Israel. Journal of Trauma \& Dissociation, 2(2), 53-66. 
Steinberg, M., Cicchetti, D., Buchanan, J., Hall, P., \& Rounsaville, B. (1993). Clinical assessment of dissociative symptoms and disorders: The Structured Clinical Interview for DSM-IV Dissociative Disorders (SCID-D). Dissociation, 6, 3-15.

Steinberg, M., Rounsaville, B., \& Cicchetti, D. (1990). The Structured Clinical Interview for DSM-III-R Dissociative Disorders: Preliminary report on a new diagnostic instrument. American Journal of Psychiatry, 147, 76-81.

Van der Hart, O., \& Dorahy, M. (in press). Dissociation: History of a concept. In P. F. Dell, \& J. O'Neil (Eds.), Dissociation and the dissociative disorders: DSM-V and beyond.

Vanderlinden, J., Van Dyck, R., Vandereycken, W., Vertommen, H., \& Verkes, R. J. (1993). The Dissociation Questionnaire (DIS-Q): Development and characteristics of a new self-report questionnaire. Clinical Psychology \& Psychotherapy, 1, 21-27.

Waller, N. G. (1996). The Dissociative Experiences Scale. In J. C. Conoley, \& J. C. Impara (Eds.), Twelfth Mental Measurements Yearbook (pp. 121-124). Lincoln, NE: Institute of Mental Measurement.

Waller, N. G., Putnam, F. W., \& Carlson, E. B. (1996). Types of dissociation and dissociative types: A taxometric analysis of dissociative experiences. Psychological Methods, 1, 300-321.

RECEIVED: $11 / 30 / 03$

REVISED: 04/25/04

$05 / 17 / 04$

ACCEPTED: 05/17/04 